\title{
Non-melanoma Skin Cancer Treated by Contact High-dose-rate Radiotherapy (Brachytherapy): A Mono-institutional Series and Literature Review
}

\author{
LUCA TAGLIAFERRI $^{1}$, FRANCESCO GIUSEPPE CIARDO ${ }^{2}$, BRUNO FIONDA $^{1 *}$, CALOGERO CASA $^{1}$, \\ ALESSANDRO DI STEFANI ${ }^{3,4}$, VALENTINA LANCELLOTTA ${ }^{1}$, ELISA PLACIDI ${ }^{1}$, GABRIELLA MACCHIA ${ }^{5}$, \\ NIKOLA DINO CAPOCCHIANO ${ }^{1}$, ALESSIO GIUSEPPE MORGANTI ${ }^{6,7}$, GYÖRGY KOVÁCS $^{8}$, \\ FRANCESCO BUSSU ${ }^{9,10}$, KETTY PERIS ${ }^{3,4}$ and VINCENZO VALENTINI ${ }^{1,2}$ \\ ${ }^{1}$ U.O.C. Radioterapia Oncologica, Dipartimento di Diagnostica per Immagini, \\ Radioterapia Oncologica ed Ematologia, Fondazione Policlinico Universitario “A. Gemelli" IRCCS, Rome, Italy; \\ ${ }^{2}$ Istituto di Radiologia, Università Cattolica del Sacro Cuore, Rome, Italy; \\ ${ }^{3}$ U.O.C. Dermatologia, Dipartimento di Scienze Mediche e Chirurgiche, \\ Fondazione Policlinico Universitario "A. Gemelli" IRCCS, Rome, Italy; \\ ${ }^{4}$ Istituto di Dermatologia, Università Cattolica del Sacro Cuore, Rome, Italy; \\ ${ }^{5}$ Radiotherapy Unit, Gemelli Molise Hospital, Università Cattolica del Sacro Cuore, Campobasso, Italy; \\ ${ }^{6}$ Radiation Oncology, IRCCS Azienda Ospedaliero-Universitaria di Bologna, Bologna, Italy; \\ ${ }^{7}$ Department of Experimental, Diagnostic and Specialty Medicine-DIMES, \\ Alma Mater Studiorum University of Bologna, Bologna, Italy; \\ ${ }^{8}$ Educational Program Director Gemelli-INTERACTS, Università Cattolica del Sacro Cuore, Rome, Italy; \\ ${ }^{9}$ Divisione di Otorinolaringoiatria, Azienda Ospedaliero Universitaria, Sassari, Italy; \\ ${ }^{10}$ Department of Otorinolaringoiatria, Università degli studi di Sassari, Sassari, Italy
}

\begin{abstract}
Background/Aim: Non-melanoma skin cancers (NMSC) are the most common neoplasms worldwide and their incidence has been proven to increase in recent years and their treatment should aim at cancer cure as well as cosmetic and functional results. The aim of the study was to report the results of our mono-institutional series of highdose-rate radiotherapy (cHDR-RT) in NMSC, based on a homogenous technique and two different treatment schedules. Patients and Methods: All patients affected by NMSC who were consecutively evaluated and treated at our Interventional Oncology Center from October 2018 to August 2020, were included. Patients underwent cHDR-RT using flap
\end{abstract}

This article is freely accessible online.

Correspondence to: Bruno Fionda, MD, U.O.C. Radioterapia Oncologica, Dipartimento di Diagnostica per Immagini, Radioterapia Oncologica ed Ematologia, Fondazione Policlinico Universitario "A. Gemelli” IRCCS, Rome, Italy. Tel: +390630154981, e-mail: bruno.fionda@yahoo.it

Key Words: Non-melanoma skin cancer, radiotherapy, brachytherapy, radiation therapy. applicators and remotely afterloaded Ir-192 sources. Results: Overall, 51 patients were treated for a total of 67 lesions. Local control (LC) and disease-specific survival (DSS) were $94.0 \%$ and $100 \%$, respectively. Grade 1, grade 2, grade 3 and grade 4 acute toxicity rates were $24.6 \%, 3.5 \%, 3.5 \%$, and $0.0 \%$, respectively. The cosmetic results were graded as excellent/good, fair, and poor in $73.7 \%, 19.3 \%$, and $7.0 \%$. Conclusion: cHDR-RT of NMSC is an effective alternative to surgery due to excellent outcomes both in terms of local control and aesthetic results especially in the face.

Non-melanoma skin cancers (NMSC) are the most common neoplasms worldwide and their incidence has been proven to increase in the recent years (1). The two most frequent NMSC are squamous cell carcinoma (SCC) and basal cell carcinoma (BCC). Albeit with a better prognosis than other cancers, the NMSC treatment strategies should be properly selected considering the possible negative impact on quality of life of suboptimal cosmetic results (2). Therefore, treatment of NMSC should aim at cancer cure as well as cosmetic and functional results (3). Therapeutic options include surgery, radiotherapy (RT), and topical agents. More recently for locally advanced or metastatic tumors where curative surgery and curative radiotherapy are not feasible, 
systemic agents such as hedgehog pathway inhibitors for BCC and immune checkpoint inhibitors for SCC are proposed $(4,5)$. RT is generally indicated in the following situations: i) exclusive therapy of tumors in anatomical sites where surgical excision might have a poor cosmetic outcome; ii) adjuvant treatment in case of positive surgical margins or high risk of recurrence (4-6).

There is a large number of clinical studies on RT of NMSC. However, most evidence come from retrospective series $(7,8)$ and the efficacy of contact high-dose-rate radiotherapy (cHDR-RT, brachytherapy) should be better investigated especially in terms of optimal treatment schedules and techniques. Therefore, the aim of this study was to report the results of our mono-institutional series of HDR contact radiotherapy in NMSC, based on a homogenous technique (flap applicators) and two different treatment schedules.

\section{Patients and Methods}

All NMSC patients treated at our Interventional Oncology Center (IOC) (9) with cHDR-RT based on flap applicators and remote afterloaded Ir-192 sources were considered.

Eligibility criteria were as follows: patients with NMSC without infiltration of deep structures. Histological confirmation was always performed except in cases of clinically relevant risk (e.g., elderly patients on anticoagulation therapy) or expected cosmetic sequelae or in case of patient refusal. For lesions with high-risk clinical features (thickness $>4 \mathrm{~mm}$ or diameter $>20 \mathrm{~mm}$ ) or histological high-risk features (deep dermal and/or perineural and/or lymphovascular invasion and/or moderate/poor differentiation) an additional imaging evaluation (Ultra Sound, Computed Tomography or Magnetic Resonance) was required according to primary site and related lymph node drainage (10). Exclusion criteria were as follows: advanced tumors with deep ulcer or deep dermis infiltration, and prior RT on the same anatomical site. Data were retrospectively extracted within the frame of the SKIN-COBRA (Consortium for Brachytherapy data Analysis) system (11).

Fifty-one patients were identified and therefore included in the present report. All patients were evaluated by the institutional SkinCancer Multidisciplinary Tumour Board (S-MDTB) and underwent a complete physical examination and a comprehensive clinical evaluation by a board of dermatologists experienced in skin cancers who had ruled out the feasibility or appropriateness of surgical resection or other local treatments.

The gross tumor volume (GTV) was jointly identified by dermatologists and radiation oncologists using dermatoscopy. The clinical target volume (CTV) was defined by adding to the GTV an additional margin of $5-10 \mathrm{~mm}$ or $10-20 \mathrm{~mm}$ in patients with $\mathrm{BCC}$ and SCC, respectively.

The dose prescription point was at 3-5 mm under the skin surface based on the Groupe Européen de Curiethérapie (GEC) and the European Society for Radiotherapy \& Oncology (ESTRO) recommendations. In case of advanced tumors with deep ulcer or deep dermis infiltration, patients underwent interstitial interventional or external beam radiotherapy and therefore were excluded from this analysis. Flap applicators, either directly tailored to the target surface or attached to a customized thermoplastic mask, were used according to the anatomic site. However, in all cases a bolus was used to cover the flap and to ensure the backscattering according to the TG-43 calculation $(12,13)$.

Two different fractionation schedules were used: $40 \mathrm{~Gy}, 5$ $\mathrm{Gy} /$ fraction, bis in die (BID) schedule (with a time interval $>6 \mathrm{~h}$ ) or $54 \mathrm{~Gy}, 3 \mathrm{~Gy} /$ fraction, 3 days/week regimen, based on patients' compliance and preference (14). Acute and late toxicity was assessed using the Radiation Therapy Oncology Group (RTOG) and the RTOG/European Organization for Research and Treatment of Cancer (EORTC) criteria (15). The cosmetic assessment was performed using a simplified three-point scale: 1 - Excellent/Good, 2 - Fair, and 3 - Poor. Both toxicity and cosmetic assessment were regularly recorded during each follow-up visit and jointly graded by a radiation oncologist and a dermatologist. Since high quality digital images of the treated area were acquired and stored during all visits, both the toxicity grade and the cosmetic assessment were subsequently confirmed through retrospective analysis of all pictures by the multidisciplinary board. Actuarial local control (LC), overall survival (OS), and disease-specific survival (DSS) were calculated using the Kaplan-Meier method.

\section{Results}

Overall, 67 skin lesions of 51 patients were treated between October 2018 and August 2020. Median patient age was 77 years (range $=52-97)$ with a male prevalence (male/female ratio: 39/12). Twenty-two lesions (32.8\%) were SCC and 39 lesions $(58.2 \%)$ were BCC, while 6 lesions $(9.0 \%)$ were basosquamous carcinoma. Patient characteristics are reported in Table I. Fifty-three lesions $(79.1 \%)$ were on the face. More specifically, 19 lesions (28.4\%) were on the nose, 15 (22.4\%) in the scalp region, 7 lesions $(10.4 \%)$ were located on the ear, 5 (7.5\%) involved eyelids and/or periorbital region and $4(6.0 \%)$ were in the cheek. Table II shows the list of all treated sites.

Sixty-two out of $67(93 \%)$ lesions were treated as the exclusive therapy and five (7\%) in the adjuvant setting (in all cases due to positive surgical margins). Moreover, 27 lesions (39.1\%) were treated using the $40 \mathrm{~Gy}, 5 \mathrm{~Gy} /$ fraction, BID schedule (with a time interval $>6$ hours) while 40 lesions (60.9\%) underwent the $54 \mathrm{~Gy}, 3 \mathrm{~Gy} / \mathrm{die}, 3$ days/week regimen. Median follow-up was 10 months (range $=6-27$ months). Two-year LC, calculated on a per patient basis was $94.0 \%(93.5 \%$ in the definitive and $100 \%$ in the adjuvant setting). Two-year OS and DSS were $90.2 \%$ and $100 \%$, respectively. Kaplan-Meier curves are shown in Figure 1A and B. Acute Grade $1(\mathrm{G} 1)$, grade $2(\mathrm{G} 2)$, grade (G3), and grade (G4) toxicity was recorded in $24.6 \%, 3.5 \%, 3.5 \%$, and $0.0 \%$ of lesions, respectively. In $68.4 \%$ of all treated lesions no acute toxicity was observed. Regarding late toxicity, only some few cases of chronic ulceration were recorded. However, these sequelae have only been observed in lesions already ulcerated before treatment.

In terms of cosmetic assessment, the result was scored as Excellent/Good in $73.7 \%$ of treated lesions and as Fair in $19.3 \%$ of them. Moreover, the cosmetic result was scored as 
Table I. Study population features.

\begin{tabular}{lc}
\hline Age (years) & Median: 77 (range=52-97) \\
Gender & 39 patients $(76.5 \%)$ \\
Male & 12 patients $(23.5 \%)$ \\
Female & \\
Histology & 39 lesions $(58.2 \%)$ \\
Basal cell carcinoma & 22 lesions $(32.8 \%)$ \\
Squamous cell carcinoma & 6 lesions $(9.0 \%)$ \\
Basosquamous carcinoma & \\
Dose prescription & 40 lesions $(59.7 \%)$ \\
54 Gy, 3 Gy/die, 3 days/week & 27 lesions $(40.3 \%)$ \\
40 Gy, 5 Gy/fraction, BID & Median 5 (range 2-17) \\
Number of catheters & $73.7 \%$ \\
Cosmetic results & $19.3 \%$ \\
Excellent/Good & $7.0 \%$ \\
Fair & \\
Poor & $68.4 \%$ \\
Toxicity & $24.6 \%$ \\
G0 & $3.5 \%$ \\
G1 & $3.5 \%$ \\
G2 & $0 \%$ \\
G3 & \\
G4 & \\
\hline
\end{tabular}

BID: Bis in die; G0: Grade 0; G1: Grade 1; G2: Grade 2; G3: Grade 3; G4: Grade 4.

Poor in only $7.0 \%$ of treated lesions $(3.5 \%$ were on the scalp and $3.5 \%$ on the leg).

\section{Discussion}

The two-year outcomes of our study are very encouraging and confirm the results of previous analyses reporting favorable outcomes after cHDR-RT of NMSC (16). More generally, ours and other reports show that cHDR-RT represents an effective and safe therapeutic option for NMSCs, as confirmed by their inclusion in several international guidelines published in recent years (17-18). Moreover, some literature reviews confirmed that cHDR-RT is effective in NMSC treatment, with around $97 \%$ local control rate and $94.8 \%$ excellent or good cosmetic results even in elderly patients $(19,20)$.

Regarding toxicity, it is noteworthy that, in our study, no acute toxicity was recorded in $68.0 \%$ of treated lesions and G3 acute toxicity rate was only $3.0 \%$. These results confirm the safety of cHDR-RT in the treatment of NMSC. In fact, in a recent report, $90 \%$ of patients experienced dermatitis but without any case of $>\mathrm{G} 3$ toxicity. Moreover, all acute toxic events recovered between the first and the second month after treatment end (21). In another report, the most common acute toxicities were itch $(42.0 \%)$, pain $(23.0 \%)$, xerosis $(12.0 \%)$, and alopecia $(12.0 \%)$. The authors recorded only G1 late toxicities including hypopigmentation (15.4\%), itch $(8.0 \%)$, mild erythema $(7.0 \%)$, and telangiectasia $(7.0 \%)$ (16). In another series late toxicities were even lower
Table II. Lesion sites.

\begin{tabular}{lc}
\hline Face & \\
Nose & $19(28.4 \%)$ \\
Scalp & $15(22.4 \%)$ \\
Ear & $7(10.4 \%)$ \\
Eyelid and periorbital region & $5(7.4 \%)$ \\
Cheek & $4(6.0 \%)$ \\
Front & $3(4.4 \%)$ \\
Other body sites & \\
Leg & $4(6.0 \%)$ \\
Back & $2(3.0 \%)$ \\
Deltoid/pectoral region & $1(1.5 \%)$ \\
Clavicular region & $1(1.5 \%)$ \\
Paravertebral region & $1(1.5 \%)$ \\
Suprascapular region & $1(1.5 \%)$ \\
Arm & $1(1.5 \%)$ \\
Hand & $1(1.5 \%)$ \\
Shoulder & $1(1.5 \%)$ \\
Neck & $1(1.5 \%)$ \\
\hline
\end{tabular}

including erythema (4.4\%), chronic ulceration (4.0\%), telangiectasia (2.6\%), and pigmentation changes (2.2\%) (22). However, particular caution should be addressed to those rare cases with factors able to prolong healing such as very large and ulcerated lesions, poorly vascularization sites, areas with frequent traumas (usually the lower extremities), or patients with vascular disorders (typically diabetes). In fact, in these cases, also chronic ulcerations may occur $(23,24)$.

Furthermore, additional considerations concerning the advantages of interventional radiotherapy (interstitial) in mucosal midface SCCs arising at the junction with skin surfaces, typically at the level of the lips, buccal mucosa and nose vestibule, also fully apply to NMSC arising in the same area and treated by cHDR-RT $(25,26)$. In fact, surgical reconstruction of these areas, and in particular of the nose tip, is notoriously extremely difficult because of the exposure and the high aesthetic impact of minimal imperfections on one hand, and of the extremely complex pattern of relieves and hollows created by the nose cartilage and underlying maxillary and nasal bones, on the other. Therefore, preservation of the osteocartilaginous framework, which is pretty resistant to radiation, by cHDR-RT, is the most successful therapeutic option in midface malignancies from functional and aesthetic points of view (27).

There is evidence in the literature, coming also from prospective studies, that hypofractionated regimens are equivalent to more protracted schedules in terms of local control (26). However, protracted schedules have the benefit of lower acute and late toxicities and better cosmetic outcomes $(28,29)$. In particular some authors suggested the limit of 3 Gy per fraction as the maximum acceptable cutoff to achieve the better safety and cosmetic results (30). 

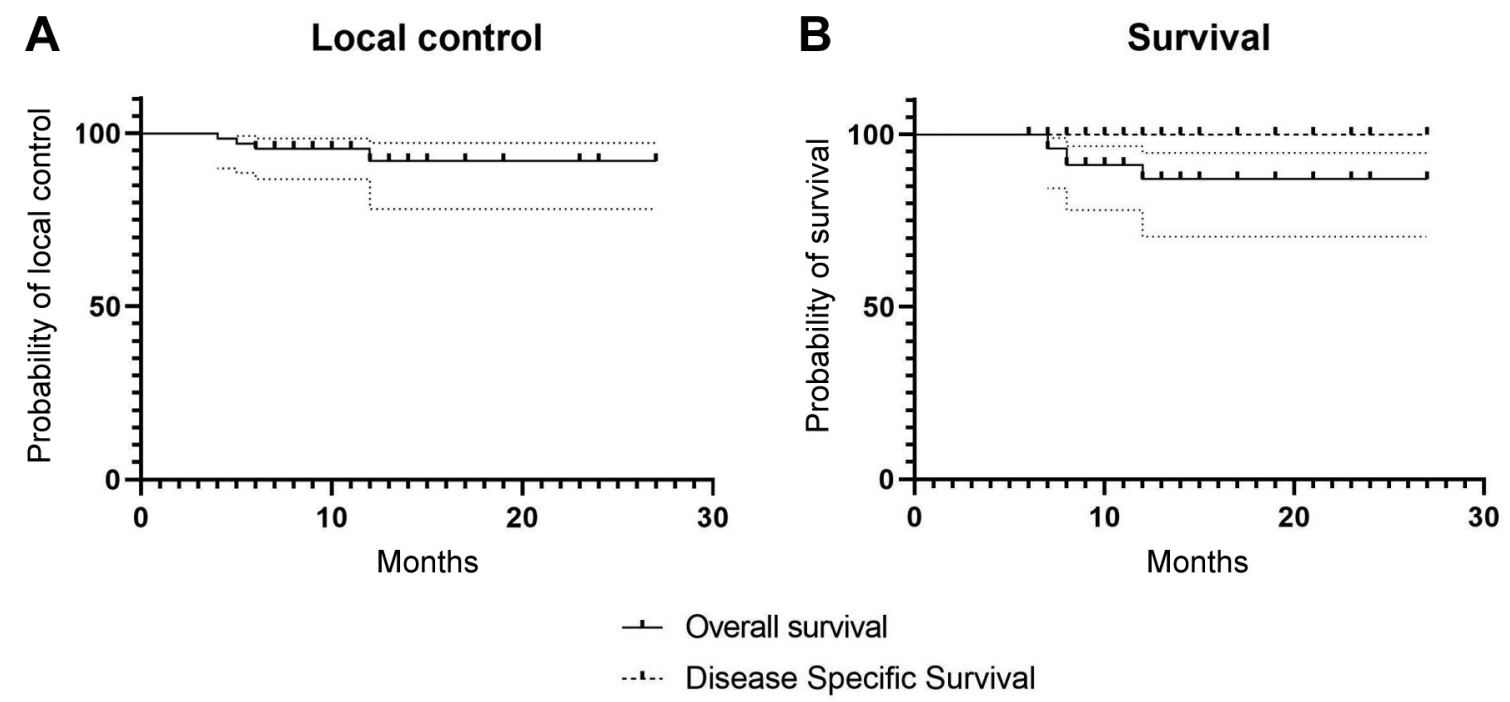

Figure 1. Kaplan-Meier curves. A. Actuarial local control. B. Actuarial overall survival and disease-specific survival.

Nevertheless, our study showed excellent results in terms of cosmetics and toxicity even though over $40 \%$ of lesions were treated with a hypofractionated-accelerated regimen.

cHDR-RT seems particularly advantageous in some specific settings. First of all, it offers clear advantages in anatomical sites where organs at risk are very close to the target such as the eyelids, as shown by a systematic review about this topic (31). In particular, when dealing with eyelid NMSC, it is advisable to use ocular shields to further reduce the amount of dose reaching the eye (32). More generally, facial lesions are probably the most suitable for cHDR-RT being usually located on curved surface and near to organs at risk $(33,34)$. Secondly, cHDR-RT is particularly useful and safe in older patients and the slight difference between OS and DSS registered in our study confirms such results because no patients died of NMSC but a few died of concomitant diseases. Finally, it should be noted that, due to the reduction in the number of fractions, c-HDR-RT is particularly useful in the present COVID-19 era while reducing the number of hospital visits (35).

Despite the aforementioned advantages, especially in some settings, it should be noted that cHDR-RT has a limited spread in the clinical practice across the different countries $(36,37)$. However, it is interesting to note the actual trend on the use of cHDR-RT in NMSC, showing a renewed interest (38). In particular, cHDR-RT has been demonstrated to be a valid therapeutic option especially in cases of extreme stress for the health systems (39).

The results of a recent survey in North American and European centers confirmed that cHDR-RT holds a huge potential given that it allows a convenient and safe treatment of NMSC. Two interesting findings of that survey were the routine estimation of lesions depth via ultrasound before treatment start, by about $60 \%$ of the responders, and a trend towards increased number of fractions for larger targets. However, an important highlighted limitation was the significant variation in the pattern of care, especially regarding planning parameters used to evaluate and compare different treatment plans (40).

In a previous survey performed across Canadian Centers, the most frequently reported reasons to choose cHDR-RT over external beam RT were the irregular lesions shape, tumor located on curved surfaces or close to organs at risk, or very small lesion size making impractical the latter technique. The only absolute contraindication to cHDR-RT was the lesion depth (no more than $5 \mathrm{~mm}$ ) while, on the contrary, tumor size, lymphatic invasion, vascular invasion, grade of differentiation, histologic subtype, and previous topical therapy were not considered as contraindications (41).

Considering the recent success achieved with anticancer immunotherapies including immune checkpoint inhibitors, the combination of cHDR-RT and immunotherapy has emerged as an exciting field of research with the potential for significant clinical benefit (42).

Regarding the limitations of the results presented in this study some relevant considerations need to be addressed. First, the retrospective design, potentially leading to selection and evaluation bias. However, it should be considered that data were collected prospectively, and that all evaluations (local control, toxicity, cosmetics) were performed in a multidisciplinary setting and subjected to an independent check by the tumor board. Another limitation is represented by the small sample size, which has prevented a thorough subgroup analysis based on setting and treatment regimen. Finally, our positive results were recorded in a highly 
selected patient population treated in a multidisciplinary setting. Therefore, our findings cannot be generalized to more advanced NMSC patients or to Centers where patients are not managed by a multidisciplinary team.

Despite these limitations, our study confirms the optimal results in terms of tumor control, cosmetics, and tolerability of cHDR-RT in NMSC. These results justify further trials aimed to define: i) the optimal radiotherapy regimen, in terms of dose and fractionation, according to setting and tumor characteristics; ii) the optimal criteria for the selection of patients to be referred to cHDR-RT. These studies could be based on the development of predictive models based on large databases aimed to improve treatment quality and efficacy, considering the high number of available clinical, molecular, and genetic parameters, and the limits in our cognitive abilities in integrating more than few variables (43). For these reasons, a GEC-ESTRO H\&N and Skin Working Group project was recently activated (11).

\section{Conclusion}

The results of this study, performed through close medical interdisciplinary collaboration, confirm the efficacy and safety of c-HDR-RT and the importance of a multidisciplinary approach in NMSC management. Based on these results, cHDR-RT should be considered especially in anatomical regions where the cosmetic result is of paramount importance such as the face. In fact, quality of life represents an important issue in patients with skin cancers and the role of dermato-oncology is central to improve patient care and outcomes especially when the management is performed in a dedicated multidisciplinary team.

\section{Conflicts of Interest}

The Authors declare no conflicts of interest.

\section{Authors' Contributions}

Luca Tagliaferri: Conception of the work; Alessandro Di Stefani: Conception of the work; Francesco Bussu: Conception of the work; Elisa Placidi: Analysis of data for the work; Nikola Dino Capocchiano: Interpretation of data for the work; Francesco Giuseppe Ciardo: Acquisition of data for the work; Calogero Casà: Acquisition of data for the work; Bruno Fionda: Drafting of the work; Valentina Lancellotta: Drafting of the work; Gabriella Macchia: Drafting of the work; Alessio Giuseppe Morganti: Final approval of the version to be published; György Kovács: Final approval of the version to be published; Ketty Peris: Final approval of the version to be published; Vincenzo Valentini: Final approval of the version to be published.

\section{References}

1 Lomas A, Leonardi-Bee J and Bath-Hextall F: A systematic review of worldwide incidence of nonmelanoma skin cancer. $\mathrm{Br}$
J Dermatol 166(5): 1069-1080, 2012. PMID: 22251204. DOI: 10.1111/j.1365-2133.2012.10830.x

2 Cives M, Mannavola F, Lospalluti L, Sergi MC, Cazzato G, Filoni E, Cavallo F, Giudice G, Stucci LS, Porta C and Tucci M: Non-melanoma skin cancers: Biological and clinical features. Int J Mol Sci 21(15): 5394, 2020. PMID: 32751327. DOI: $10.3390 /$ ijms 21155394

3 Tagliaferri L, Lancellotta V, Fionda B, Panza G, Cornacchione P, Colloca G, Azario L, Mattiucci GC, Gambacorta MA and Valentini V: Subungual squamous cell carcinoma of the thumb treated by "function sparing approach" using contact radiotherapy (brachytherapy). Turk J Oncol 34: 283-286, 2019. DOI: $10.5505 /$ tjo.2019.2002

4 National Comprehensive Cancer Network: NCCN clinical practice guidelines in oncology. Squamous cell skin cancer. Version 1. 2021-February 5, 2021 ed. Available at: https:// www.nccn.org/guidelines/guidelines-detail?category=1\&id=1465 [Last accessed on April 17 2021]

5 National Comprehensive Cancer Network: NCCN clinical practice guidelines in oncology. Basal cell skin cancer. Version 2. 2021-February 25, 2021 ed. Available at: https:// www.nccn.org/guidelines/guidelines-detail?category=1\&id=1416 [Last accessed on April 17 2021]

6 Likhacheva A, Awan M, Barker CA, Bhatnagar A, Bradfield L, Brady MS, Buzurovic I, Geiger JL, Parvathaneni U, Zaky S and Devlin PM: Definitive and postoperative radiation therapy for basal and squamous cell cancers of the skin: Executive summary of an American Society for Radiation Oncology Clinical Practice Guideline. Pract Radiat Oncol 10(1): 8-20, 2020. PMID: 31831330. DOI: $10.1016 /$ j.prro.2019.10.014

7 Alam M, Nanda S, Mittal BB, Kim NA and Yoo S: The use of brachytherapy in the treatment of nonmelanoma skin cancer: a review. J Am Acad Dermatol 65(2): 377-388, 2011. PMID: 21496952. DOI: 10.1016/j.jaad.2010.03.027

8 Chargari C, Deutsch E, Blanchard P, Gouy S, Martelli H, Guérin F, Dumas I, Bossi A, Morice P, Viswanathan AN and HaieMeder C: Brachytherapy: An overview for clinicians. CA Cancer J Clin 69(5): 386-401, 2019. PMID: 31361333. DOI: 10.3322/ caac. 21578

9 Kovács G, Tagliaferri L and Valentini V: Is an Interventional Oncology Center an advantage in the service of cancer patients or in the education? The Gemelli Hospital and INTERACTS experience. J Contemp Brachytherapy 9(6): 497-498, 2017. PMID: 29441092. DOI: 10.5114/jcb.2017.72603

10 Ouhib Z, Kasper M, Perez Calatayud J, Rodriguez S, Bhatnagar A, Pai S and Strasswimmer J: Aspects of dosimetry and clinical practice of skin brachytherapy: The American Brachytherapy Society working group report. Brachytherapy 14(6): 840-858, 2015. PMID: 26319367. DOI: 10.1016/j.brachy.2015.06.005

11 Lancellotta V, Guinot JL, Fionda B, Rembielak A, Di Stefani A, Gentileschi S, Federico F, Rossi E, Guix B, Chyrek AJ, Meritxell A, Villalba SR, Colloca GF, Dinapoli N, Masciocchi C, Lenkowicz J, Capocchiano ND, Damiani A, Valentini V, Kovács $\mathrm{G}$ and Tagliaferri L: SKIN-COBRA (Consortium for Brachytherapy data Analysis) ontology: The first step towards interdisciplinary standardized data collection for personalized oncology in skin cancer. J Contemp Brachytherapy 12(2): 105110, 2020. PMID: 32395133. DOI: 10.5114/jcb.2020.94579

12 Granero D, Perez-Calatayud J, Vijande J, Ballester F and Rivard MJ: Limitations of the TG-43 formalism for skin high-dose-rate 
brachytherapy dose calculations. Med Phys 41(2): 021703, 2014 PMID: 24506594. DOI: 10.1118/1.4860175

13 Jeong J, Barker CA, Zaider M and Cohen GN: Impact of source position on high-dose-rate skin surface applicator dosimetry. Brachytherapy 15(5): 650-660, 2016. PMID: 27263059. DOI: 10.1016/j.brachy.2016.04.389

14 Guinot JL, Rembielak A, Perez-Calatayud J, Rodríguez-Villalba S, Skowronek J, Tagliaferri L, Guix B, Gonzalez-Perez V, Valentini V, Kovacs G and GEC ESTRO: GEC-ESTRO ACROP recommendations in skin brachytherapy. Radiother Oncol 126(3): 377-385, 2018. PMID: 29455924. DOI: 10.1016/ j.radonc.2018.01.013

15 Cox JD, Stetz J and Pajak TF: Toxicity criteria of the Radiation Therapy Oncology Group (RTOG) and the European Organization for Research and Treatment of Cancer (EORTC). Int J Radiat Oncol Biol Phys 31(5): 1341-1346, 1995. PMID: 7713792. DOI: 10.1016/0360-3016(95)00060-C

16 Casey S, Awotwi-pratt $\mathrm{J}$ and Bahl G: Surface mould brachytherapy for skin cancers: The British Columbia cancer experience. Cureus, 2019. DOI: 10.7759/cureus.6412

17 Peris K, Fargnoli MC, Garbe C, Kaufmann R, Bastholt L, Seguin NB, Bataille V, Marmol VD, Dummer R, Harwood CA, Hauschild A, Höller C, Haedersdal M, Malvehy J, Middleton MR, Morton CA, Nagore E, Stratigos AJ, Szeimies RM, Tagliaferri L, Trakatelli M, Zalaudek I, Eggermont A, Grob JJ and European Dermatology Forum (EDF), the European Association of Dermato-Oncology (EADO) and the European Organization for Research and Treatment of Cancer (EORTC): Diagnosis and treatment of basal cell carcinoma: European consensus-based interdisciplinary guidelines. Eur J Cancer 118: 10-34, 2019. PMID: 31288208. DOI: 10.1016/j.ejca.2019.06.003

18 Fulkerson RK, Perez-Calatayud J, Ballester F, Buzurovic I, Kim Y, Niatsetski Y, Ouhib Z, Pai S, Rivard MJ, Rong Y, Siebert FA, Thomadsen BR and Weigand F: Surface brachytherapy: Joint report of the AAPM and the GEC-ESTRO Task Group No. 253. Med Phys 47(10): e951-e987, 2020. PMID: 32862452. DOI: $10.1002 / \mathrm{mp} .14436$

19 Lancellotta V, Kovács G, Tagliaferri L, Perrucci E, Rembielak A, Stingeni L, Tramontana M, Hansel K, Colloca G, Saldi S, Valentini $\mathrm{V}$ and Aristei C: The role of personalized Interventional Radiotherapy (brachytherapy) in the management of older patients with non-melanoma skin cancer. J Geriatr Oncol 10(3): 514-517, 2019. PMID: 30314955. DOI: 10.1016/ j.jgo.2018.09.009

20 Delishaj D, Rembielak A, Manfredi B, Ursino S, Pasqualetti F, Laliscia C, Orlandi F, Morganti R, Fabrini MG and Paiar F: Non-melanoma skin cancer treated with high-dose-rate brachytherapy: a review of literature. J Contemp Brachytherapy 8(6): 533-540, 2016. PMID: 28115960. DOI: 10.5114/ jcb.2016.64112

21 Campos A, Pérez H, Lora D, Cabezas A, Rodriguez V, Gascon N, Guardado S and Pérez-regadera J: Non-melanoma skin cancer treated with HDR-brachytherapy: Acute toxicity and cosmesis outcomes. Brachytherapy 15: S67, 2018. DOI: 10.1016/ j.brachy.2016.04.096

22 Olek D Jr, El-Ghamry MN, Deb N, Thawani N, Shaver C and Mutyala S: Custom mold applicator high-dose-rate brachytherapy for nonmelanoma skin cancer-An analysis of 273 lesions. Brachytherapy 17(3): 601-608, 2018. PMID: 29398593. DOI: $10.1016 /$ j.brachy.2018.01.002
23 Rembielak A: Complex and prolonged skin toxicity after superficial brachytherapy for basal cell carcinoma on the lower leg. J Contemp Brachytherapy 12(4): 406-411, 2020. PMID: 33293981. DOI: $10.5114 /$ jcb.2020.98121

24 Ferro M, Deodato F, Macchia G, Gentileschi S, Cilla S, Torre G, Padula GD, Nuzzo M, Massaccesi M, Valentini V and Morganti AG: Short-course radiotherapy in elderly patients with early stage non-melanoma skin cancer: a phase II study. Cancer Invest 33(2): 34-38, 2015. PMID: 25608635. DOI: 10.3109/ 07357907.2014.998835

25 Bussu F, Tagliaferri L, Mattiucci G, Parrilla C, Rizzo D, Gambacorta MA, Lancellotta V, Autorino R, Fonnesu C, Kihlgren C, Galli J, Paludetti G, Kovács G and Valentini V: HDR interventional radiotherapy (brachytherapy) in the treatment of primary and recurrent head and neck malignancies. Head Neck 41(6): 1667-1675, 2019. PMID: 30701614. DOI: 10.1002/hed.25646

26 Tagliaferri L, Bussu F, Fionda B, Catucci F, Rigante M, Gambacorta MA, Autorino R, Mattiucci GC, Miccichè F, Placidi E, Balducci M, Galli J, Paludetti G, Kovacs G and Valentini V: Perioperative HDR brachytherapy for reirradiation in head and neck recurrences: single-institution experience and systematic review. Tumori 103(6): 516-524, 2017. PMID: 28291904. DOI: $10.5301 / \mathrm{tj} .5000614$

27 Tagliaferri L, Fionda B, Bussu F, Parrilla C, Lancellotta V, Deodato F, Cammelli S, Boldrini L, Gambacorta MA, Morganti AG, Valentini V, Paludetti G, Peris $K$ and Kovacs G: Interventional radiotherapy (brachytherapy) for squamous cell carcinoma of the nasal vestibule: a multidisciplinary systematic review. Eur J Dermatol 29(4): 417-421, 2019. PMID: 31486400. DOI: $10.1684 /$ ejd.2019.3599

28 Gauden R, Pracy M, Avery AM, Hodgetts I and Gauden S: HDR brachytherapy for superficial non-melanoma skin cancers. J Med Imaging Radiat Oncol 57(2): 212-217, 2013. PMID: 23551783. DOI: $10.1111 / \mathrm{j} .1754-9485.2012 .02466 . \mathrm{x}$

29 Rio E, Bardet E, Ferron C, Peuvrel P, Supiot S, Campion L, De Montreuil CB, Mahe MA and Dreno B: Interstitial brachytherapy of periorificial skin carcinomas of the face: a retrospective study of 97 cases. Int J Radiat Oncol Biol Phys 63(3): 753-757, 2005. PMID: 15927410. DOI: 10.1016/j.ijrobp. 2005.03 .027

30 Kalaghchi B, Esmati E, Ghalehtaki R, Gomar M, Jaberi R, Gholami S, Babaloui S, Nabavi M, Sotoudeh S, Khanjani N, Kazemian A, Amouzegar-Hashemi F, Aghili M and Lashkari M: High-dose-rate brachytherapy in treatment of non-melanoma skin cancer of head and neck region: preliminary results of a prospective single institution study. J Contemp Brachytherapy 10(2): 115-122, 2018. PMID: 29789760. DOI: 10.5114/jcb. 2018.75596

31 Frakulli R, Galuppi A, Cammelli S, Macchia G, Cima S, Gambacorta MA, Cafaro I, Tagliaferri L, Perrucci E, Buwenge M, Frezza G, Valentini V and Morganti AG: Brachytherapy in non melanoma skin cancer of eyelid: a systematic review. J Contemp Brachytherapy 7(6): 497-502, 2015. PMID: 26816508. DOI: $10.5114 /$ jcb.2015.56465

32 Vavassori A, Riva G, Durante S, Fodor C, Comi S, Cambria R, Cattani F, Spadola G, Orecchia R and Jereczek-Fossa BA: Mould-based surface high-dose-rate brachytherapy for eyelid carcinoma. J Contemp Brachytherapy 11(5): 443-448, 2019. PMID: 31749853 . DOI: $10.5114 /$ jcb.2019.88619 
33 Guix B, Finestres F, Tello J, Palma C, Martinez A, Guix J and Guix R: Treatment of skin carcinomas of the face by high-doserate brachytherapy and custom-made surface molds. Int J Radiat Oncol Biol Phys 47(1): 95-102, 2000. PMID: 10758310. DOI: 10.1016/s0360-3016(99)00547-7

34 Jumeau R, Renard-Oldrini S, Courrech F, Buchheit I, Oldrini G, Vogin $G$ and Peiffert D: High dose rate brachytherapy with customized applicators for malignant facial skin lesions. Cancer Radiother 20(5): 341-346, 2016. PMID: 27321412. DOI: 10.1016/j.canrad.2016.03.008

35 Tagliaferri L, Di Stefani A, Schinzari G, Fionda B, Rossi E, Del Regno L, Gentileschi S, Federico F, Valentini V, Tortora G, Peris $\mathrm{K}$ and Gemelli Skin-Cancer Multidisciplianry Tumour Board (SMDTB): Skin cancer triage and management during COVID-19 pandemic. J Eur Acad Dermatol Venereol 34(6): 1136-1139, 2020. PMID: 32333832. DOI: 10.1111/jdv.16529

36 Autorino R, Vicenzi L, Tagliaferri L, Soatti C, Kovacs PG and Aristei C: A national survey of AIRO (Italian Association of Radiation Oncology) brachytherapy (Interventional Radiotherapy) study group. J Contemp Brachytherapy 10(3): 254-259, 2018. PMID: 30038646. DOI: $10.5114 /$ jcb.2018.76981

37 Tagliaferri L, Vavassori A, Lancellotta V, De Sanctis V, Barbera F, Fusco V, Vidali C, Fionda B, Colloca G, Gambacorta MA, Aristei C, Corvò R and Magrini SM: Can brachytherapy be properly considered in the clinical practice? Trilogy project: The vision of the AIRO (Italian Association of Radiotherapy and Clinical Oncology) Interventional Radiotherapy study group. J Contemp Brachytherapy 12(1): 84-89, 2020. PMID: 32190074. DOI: $10.5114 / \mathrm{jcb} .2020 .92765$

38 Ota K, Adar T, Dover L and Khachemoune A: Review: the reemergence of brachytherapy as treatment for non-melanoma skin cancer. J Dermatolog Treat 29(2): 170-175, 2018. PMID: 28604229. DOI: 10.1080/09546634.2017.1341617
39 Williams VM, Kahn JM, Thaker NG, Beriwal S, Nguyen PL, Arthur D, Petereit D and Dyer BA: The case for brachytherapy: Why it deserves a renaissance. Adv Radiat Oncol 6(2): 100605, 2021. PMID: 33723523. DOI: 10.1016/j.adro.2020.10.018

40 Likhacheva AO, Devlin PM, Shirvani SM, Barker CA, Beron P, Bhatnagar A, Doggett SW, Hochman L, Hsu C, Kasper M, Keisch M, Mutyala S, Prestidge B, Rodriguez Villalba S, Shukla V, Sundararaman S and Kamrava M: Skin surface brachytherapy: A survey of contemporary practice patterns. Brachytherapy 16(1): 223-229, 2017. PMID: 27908679. DOI: 10.1016/j.brachy.2016.10.006

41 Rose JN, McLaughlin PY, Hanna TP, D’Souza D, Sur R and Falkson CB: Surface mold brachytherapy for nonmelanoma skin cancer: Canadian patterns of practice. Pract Radiat Oncol 4(6): 398-403, 2014. PMID: 25407861. DOI: 10.1016/j.prro. 2013.12.003

42 Rallis KS, Lai Yau TH and Sideris M: Chemoradiotherapy in cancer treatment: Rationale and clinical applications. Anticancer Res 41(1): 1-7, 2021. PMID: 33419794. DOI: 10.21873/ anticanres. 14746

43 Lambin P, van Stiphout RG, Starmans MH, Rios-Velazquez E, Nalbantov G, Aerts HJ, Roelofs E, van Elmpt W, Boutros PC, Granone P, Valentini V, Begg AC, De Ruysscher D and Dekker A: Predicting outcomes in radiation oncology-multifactorial decision support systems. Nat Rev Clin Oncol 10(1): 27-40, 2013. PMID: 23165123. DOI: 10.1038/nrclinonc.2012.196

Received April 19, 2021

Revised May 11, 2021

Accepted May 21, 2021 